\title{
Posttreatment of Olive Mill Wastewater by Immobilized $\mathrm{TiO}_{2}$ Photocatalysis
}

\author{
José C. Costa* and M. Madalena Alves \\ Institute for Biotechnology and Bioengineering (IBB), Centre of Biological Engineering, Universidade do Minho, Braga, \\ Portugal
}

Received 26 July 2012, accepted 20 November 2012, DOI: 10.1111/php.12023

\begin{abstract}
A photocatalytic reactor with $\mathrm{UV} / \mathrm{TiO}_{2}$ was used for the posttreatment of olive mill wastewater after anaerobic digestion. A factorial experimental design was adopted to determine the statistical significance of each parameter tested, namely, initial chemical oxygen demand (COD), pH, treatment time and recirculation flow and possible interactions in three response variables: phenols, color and COD removals. Removal efficiencies of $\mathbf{9 0 . 8} \pm \mathbf{2 . 7 \%}, \mathbf{7 9 . 3} \pm \mathbf{1 . 9 \%}$ and $50.3 \pm 6.3 \%$ were obtained for total phenols (TPh), color and COD respectively. TPh and color were almost completely removed after $24 \mathrm{~h}$ of treatment, while the COD removal was partial. Because increasing the treatment time is economically unfeasible a recirculation to the anaerobic reactor should be considered. Regarding the most significant variables, the TPh removal efficiency is dependent of the initial COD concentration; the color removal efficiency decreased with increasing $\mathrm{COD}$ concentration and $\mathrm{pH}$; and, the COD removal efficiency is directly linked with the treatment time. The interaction between the initial COD and treatment time affect negatively the response variables tested because of the inactivation of some active sites of the $\mathrm{TiO}_{2}$ paper.
\end{abstract}

\section{INTRODUCTION}

Olive oil has been considered a fundamental ingredient of a healthy diet, especially in the Mediterranean area. A significant increase in production during the last years was observed. Therefore, one of the major concerns of olive oil industry is the treatment of high amounts of generated olive oil mill wastewater (OMW). Its annual production is in the range of some million cubic meters throughout the European Union (1). Oil mill wastewater (OMW) is heavy polluted and hence it cannot be disposed in the environment without any treatment (2). However, a common way of dealing with OMW is to discharging it directly into the sewer, confine it in a central lagoon or store it in a small pond nearby the mill, where it is left to evaporate until the next season. These ponds are often leaking causing ground water pollution and malodor. The setting up of more stringent regulations

*Corresponding author email: carloscosta@deb.uminho.pt (José Carlos Costa) (C) 2012 Wiley Periodicals, Inc.

Photochemistry and Photobiology (C) 2012 The American Society of Photobiology 0031-8655/13
(Table 1) concerning public waste disposal, imposed higher interests in development of new technologies and procedures for the purification of OMW (3). Among those processes, biological methods, whether aerobic (4) or anaerobic (5), have been recognized as viable options. Due to high contents of chemical oxygen demand (COD), up to $220 \mathrm{~g} \mathrm{~L}^{-1}$ (6), OMW can be an excellent substrate for renewable energy production, such as in anaerobic digestion (AD) processes, which produce biogas (7) and biohydrogen.

The main problems of OMW are the high lipidic and phenolic compounds concentration. Phenols can go from 1 to $24 \mathrm{~g} \mathrm{~L}^{-1}$ (8). These characteristics may cause an inhibitory effect when OMW is directly used in an anaerobic treatment. Phenolic compounds are considered one of the major problems associated with OMW not only due to their recalcitrance but also because of their strong brown to dark color. The combination of environmental and economic advantages makes the use of biological treatments and advanced oxidation processes (AOP) a suitable solution for the removal of toxic and colored compounds from water (2). AOP are based on the use of the hydroxyl radical $\left(\mathrm{OH}^{\circ}\right)$ as primary oxidant of organic pollutants. Photocatalysis is an emerging AOP process (9). The main mechanism of photocatalysis is the formation of highly reactive and nonselective hydroxyl radicals upon irradiation of semiconductor particles with near UV radiation (wavelength $[\lambda]<400 \mathrm{~nm}$ ). The photogenerated electron/hole pairs $\left(\mathrm{e}^{-} / \mathrm{h}^{+}\right)$are used as reducing/ oxidizing agents as they can migrate to the surface of the semiconductor particle to form oxidizing species in the presence of oxygen. The positively charged holes oxidize the organic compounds adsorbed on the catalyst surface. In addition, hydroxyl radicals are produced in aqueous system. The hydroxyl radicals serve as a strong oxidizing agent for the conversion of organic molecules to carbon dioxide (10). Due to its stability $\mathrm{TiO}_{2}$ is accepted to be one of the most suitable semiconductors for photocatalysis. It is the most studied, however, a large band gap $(3.2 \mathrm{eV})$ of anatase $\mathrm{TiO}_{2}$ restricts its use to the narrow lightresponse range of UV light $(\lambda<400 \mathrm{~nm}$, only about $3-5 \%$ of total sunlight). Nevertheless, efforts are reported in the literature to decrease the band gap of $\mathrm{TiO}_{2}$ and improve its activity under visible light $(11,12)$. This can significantly improve the energy demand of advanced oxidation technologies and overcome its main drawback, i.e. high energetic costs. The fundamentals of photocatalysis, employing the semiconductor $\mathrm{TiO}_{2}$ as catalyst, have been extensively reported $(9,10,13)$. The process is suitable for wastewater remediation because it occurs under ambient conditions, it avoids the formation of photocatalyzed intermediate 
Table 1. Independent and response variables tested with respective initial high and low values used in the factorial experimental design and Portuguese legislation limits.

\begin{tabular}{|c|c|c|c|c|}
\hline Variable & Units & Minimum $(-1)$ & Maximum $(+1)$ & Legislation limits* \\
\hline COD & $\mathrm{mg} \mathrm{L}^{-1}$ & 1051 & 7370 & 150 \\
\hline $\mathrm{pH}$ & & 4.8 & 7.5 & $6.0-9.0$ \\
\hline$t_{\text {treatment }}$ & hour & 8 & 24 & n.a. \\
\hline$t_{\text {contact }}$ & minute & 1 & 2 & n.a. \\
\hline $\mathrm{TPh}$ & $\mathrm{mg} \mathrm{L}^{-1}$ & 129 & 400 & 0.5 \\
\hline Color & $\mathrm{cm}^{-1}$ & 2.58 & 5.12 & Undetectable at a dilution of $1: 20$ \\
\hline
\end{tabular}

*Portuguese "Decreto-Lei no. 236/98, from 1/08/1998"- emission limit value that should not be exceeded for wastewater discharge.

n.a.- not applicable.

stable products unlike direct photolysis techniques, and the oxidation of the substrates to $\mathrm{CO}_{2}$ is complete. Because it is an inexpensive technology with a high turnover, it offers great potential as an industrial technology to detoxify wastewaters (10). Although $\mathrm{TiO}_{2}$ is widely used in suspension with excellent performance, it requires expensive filtration to separate the catalyst from the treated water. To avoid this drawback, $\mathrm{TiO}_{2}$ has been used immobilized on different types of supports $(14,15)$.

Optimization of a photocatalytic process is difficult due to several interactions between the main variables controlling the process. To address the above concerns, and meet the demands of a structured research, proper experimental design techniques considering all factors and their possible interactions must be performed. Factorial experiments design allows to study the process behavior under conditions in which independent variables, called in this context factors, are varied simultaneously. Thus, it is possible to investigate the joint effect of two or more factors on a dependent variable. The factorial design also facilitates the study of interactions, giving insights on the effects of different conditions tested, on the identifiable subgroups of subjects participating in the experiment. The use of factorial designs leads to optimized parameters with a minimum set of experiments and to the possibility of obtaining a polynomial expression that describes the process yield (16).

The aim of this work is to study the photocatalytic oxidation of anaerobically pretreated OMW, regarding the effect of various operating conditions (initial $\mathrm{COD}, \mathrm{pH}$, treatment time and recirculation flow) on the removal of color, phenolic and organic compounds. A factorial design methodology was adopted to determine in a systematic way the statistical significance of each parameter and possible interactions.

\section{MATERIALS AND METHODS}

Olive mill wastewater. Olive oil mill wastewater used in these experiments was originated in a lab-scale up-flow anaerobic reactor of $2.5 \mathrm{dm}^{3}$ (useful volume). The reactor consisted in an anaerobic chamber and an external jacket, which kept the temperature at $37^{\circ} \mathrm{C}$. A solid-gas-liquid separator was connected at the middle of the reactor to avoid washout and to promote the degradation of the accumulated substrate onto the biomass (17). The effluent was immediately frozen until further use.

Photocatalytic reactor. The photocatalytic reactor (Fig. 1) consisted in a $37^{\circ}$ slanted aluminum plate with a working area of $30 \times 30 \mathrm{~cm}^{2}$ $(18,19)$. Coating it with a thin layer of polytetrafluoroethylene (PTFE) inactivated the aluminum surface. The solution to be treated flowed as a thin film from the top of the chamber over a nonwoven fabric made of cellulose fibers on which Tiona PC500 $\mathrm{TiO}_{2}\left(18 \mathrm{~g} \mathrm{~m}^{-2}\right)$, UOP 2000 zeolite $\left(2 \mathrm{~g} \mathrm{~m}^{-2}\right)$ and Snowtex $50 \mathrm{SiO}_{2}\left(20 \mathrm{~g} \mathrm{~m}^{-2}\right)$ have been fixed by compression (gift from Ahlstrom, Pont-Evêque, France). PC500 titania by Millennium Inorganic Chemicals was used (anatase: $>99 \%$; surface area $>250 \mathrm{~m}^{2} \mathrm{~g}^{-1}$, crystallites mean size $=5-10 \mathrm{~nm}$ ). Titania PC500 was coated on nonwoven paper (natural and synthetic fibers, $2 \mathrm{~mm}$ thick) using an inorganic binder. The binder was an aqueous dispersion of colloidal $\mathrm{SiO}_{2}$ (EP1069950B1 European patent) (19). A transparent glass sheet covered the reacting chamber to avoid evaporation of the solution. The treated sample $(300 \mathrm{~mL})$ was stored in a reservoir and continuously circulated in the system by a peristaltic pump, thereby permitting optimal distribution of the liquid over the catalytic support. PTFE tubing was used. The reservoir was open to air and the sample constantly agitated to ensure sufficient oxygenation. Artificial irradiation was provided by two UV lamps emitting light with a wavelength around $365 \mathrm{~nm}$ (F15T8, BLB 15W; Duke, Essen, Germany). The lights were positioned in parallel to the reactor. Light was turned on at the beginning of each experiment. After each experimental run, the photocatalytic reactor was rinsed with de-ionized water under UV irradiation. The photocatalytic reactor using an immobilized catalyst avoids the need of a final step of filtration for the extraction of the catalyst from the effluent.

Analytical methods. Total COD was determined using test kits (Hach Lange, Düsseldorf, Germany). Total and volatile suspended solids (TSS and VSS) were determined according to Standard Methods (20). Total phenolic (TPh) content was determined colorimetrically at $765 \mathrm{~nm}$ on a spectrophotometer (Hach Lange). The Folin-Ciocalteau reagent was used according to the procedures described in (21). Gallic acid monohydrate was used as standard to quantify the concentration of total phenols in OMW. UV-Visible spectrophotometry using a JASCO V-560 device in the range $200-800 \mathrm{~nm}$, measured sample absorbance. Changes in sample absorbance at the wavelength of $390 \mathrm{~nm}$ were monitored to assess the extent of decolorization occurring during photocatalytic posttreatment.

Factorial experimental design. A statistical approach was chosen based on a factorial experimental design to infer about the effects of four variables on the treatment performance and possible interaction effects. Four independent variables $\left(X_{1}-X_{4}\right)$, which typically affect the efficiency of photocatalysis, in general, and the photocatalytic reactor used, in particular, were taken into account. The variables (Table 1) were the initial COD concentration, initial $\mathrm{pH}$, treatment time ( $\left.t_{\text {treatment }}\right)$ and cycle duration expressed as the time that takes to the sample volume pass through the reactor $\left(t_{\text {contact }}=\right.$ Volume/Flow $)$. In this study, the initial TPh concentration and color are dependent of the initial COD and therefore were not considered as independent variables. The $\mathrm{pH}$ limits imposed correspond to the $\mathrm{pH}$ of the samples coming from the anaerobic digestion step $(+1)$ and the $\mathrm{pH}$ of the raw OMW $(-1)$. It was adjusted with $\mathrm{HCl} 8 \mathrm{M}$. The photocatalysis efficiency was assessed in terms of response factors, namely, TPh removal $\left(Y_{1}\right)$, Color removal at $\lambda=390 \mathrm{~nm}\left(Y_{2}\right)$ and COD removal $\left(Y_{3}\right)$.

The experimental design consisted in a full factorial experimental set with $16\left(2^{n}\right.$, with $n=4$ variables $)$ runs. The experiments were randomly performed. The software package Design-Expert ${ }^{\circledR}$ (Stat-Ease, Inc., Minneapolis) was used to perform the design matrix of the experiments and their statistical analysis. Estimation of the average effect, the main effects of each individual variable, as well as their interaction effects were determined according to Eq. (1)

$$
Y_{i}=\beta_{0}+\sum \beta_{i} \chi_{i}+\sum \beta_{i j} \chi_{i} \chi_{j}+\sum \beta_{i j k} \chi_{i} \chi_{j} \chi_{k}+\beta_{i j k l} \chi_{i} \chi_{j} \chi_{k} \chi_{l}
$$

Where $Y_{i}$ is the predicted response variable removal efficiency (\%); $\beta_{0}$ is the constant coefficient; $\beta_{i}$ is the coefficient of the variable $X_{i} ; \beta_{i j}$, $\beta_{i j k}$ and $\beta_{i j k l}$ are the interactions coefficients; and $X_{i}, X_{j}, X_{k}$ and $X_{l}$ are the independent variables. Removal efficiencies data were processed for 


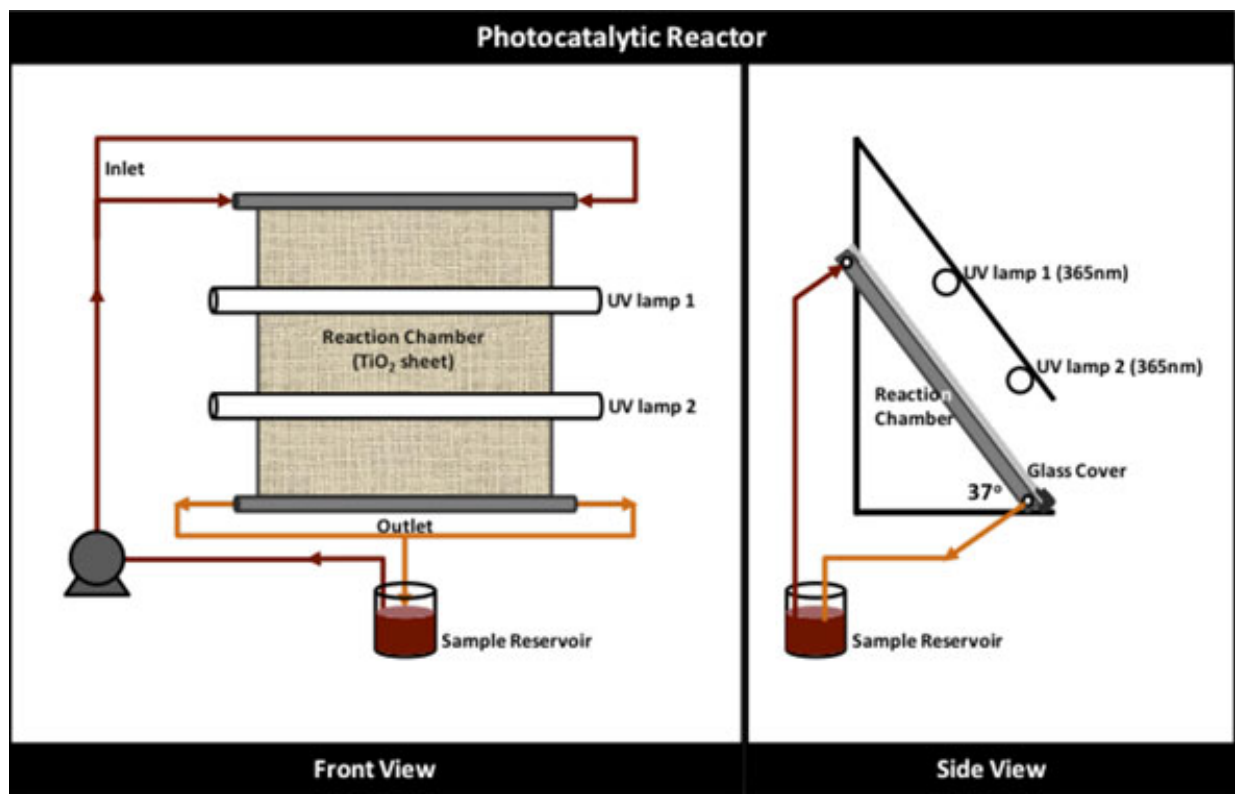

Figure 1. Schematic presentation of the photocatalytic reactor.

Eq. (1), including ANOVA to obtain the interaction between the process variables and the responses. Statistical significance was established at the $P<0.05$ level.

\section{RESULTS AND DISCUSSION}

\section{Anaerobic digestion step}

Olive oil mill wastewater samples were collected from an up-flow anaerobic reactor operating with an organic loading rate of $1.0 \pm 0.1 \mathrm{~kg} \mathrm{COD} \mathrm{m}^{-3} \mathrm{~d}^{-1}$ and a COD removal efficiency of $79 \pm 5 \%$. TPh removal was around $40 \%( \pm 10 \%)$ and the dark color was not removed during the AD step. Therefore, a subsequent step for TPh and color removal is necessary. A constrain to the photocatalytic process is the high TSS concentration present in raw OMW. The anaerobic reactor was operating with removal efficiencies of $70 \pm 5 \%$ of VSS and $40 \pm 5 \%$ of TSS when the samples were collected. A large part of the OMW solids are being retained/ degraded in the AD step representing a major advantage for the use of photocatalysis as a posttreatment. TSS at the beginning of the experiments were $215 \pm 20 \mathrm{mg} \mathrm{L}^{-1}$. Details about the anaerobic reactor operation and results are described elsewhere (17).

\section{Photocatalysis}

A statistical approach based on a factorial experimental design that would allow us to infer about the effect of four variables with a relatively small number of experiments was chosen. The classical univariate approach is suitable for factors that are independent but is time consuming because the response is investigated independently for each factor while all other factors are held at a constant level. Moreover, univariate methods do not take interactive effects between factors into account. The experimental matrix and the corresponding response variables obtained in each run are presented in Table 2.

Total phenols removal. Total phenols are one of the major problems in OMW treatment. Initial concentration of $\mathrm{TPh}$ varied between 129 and $400 \mathrm{mg} \mathrm{L}^{-1}$, which stay far away from the legislation limits imposed by the Portuguese law (Table 1). TPh are the main compounds targeted by the photocatalysis technique, therefore its removal was the first response variable studied. Initial COD decrease from 7370 to $1051 \mathrm{mg} \mathrm{L}^{-1}$ (and concomitant decrease in initial concentration of $\mathrm{TPh}$ ) caused an increase in $\mathrm{TPh}$ removal efficiency from $33 \pm 7 \%$ to $74 \pm 15 \%$ (Table 2). Initial COD was identified as the most significant variable for the model (78.9\% contribution). However, there are other significant variables, such as $t_{\text {treatment }}(13.2 \%), \mathrm{pH}(2.8 \%)$ and an interaction between COD and $t_{\text {treatment }}(4.3 \%)$. This can be described by the following model equation:

$$
Y_{1}=53.1-20.6 Z_{1}-3.9 Z_{2}+8.4 Z_{3}-4.9 Z_{1} Z_{3}
$$

where $Y_{1}$ is the total phenols removal efficiency (\%), $Z_{i}$ is the transformed forms of the independent variables according to:

$$
Z_{i}=\frac{\chi_{i}-\frac{\chi^{+}+\chi^{-}}{2}}{\frac{\chi^{+}+\chi^{-}}{2}}
$$

where $X_{i}$ is the original (untransformed) values of the variables, and $X^{+}$and $X^{-}$are the upper and lower limit value of the variables.

Equation (2) and Table 2 show that at lower concentration of $\mathrm{TPh}$ the photodegradation efficiency is high, but it decreases as the concentration increases. When the pollutant concentration increases, the radicals $\mathrm{OH}^{*}$ needed to achieve a similar degradation increases. However, the formation of hydroxyl radicals remained constant in time because the catalyst concentration and the light intensity did not change. A dependency between the photocatalysis efficiency and the initial concentration of phenol was also detected in (22). According to the authors, the competitive adsorption on the surface of $\mathrm{TiO}_{2}$ particles between the hydroxyl radicals generated by the active site $\mathrm{OH}^{-}$and phenol molecules adsorbed on the surface catalyst, which react with radicals, can affect the overall degradation rate. Slow diffusion of 
Table 2. Design matrix of the $2^{4}$ factorial experimental design and observed response factors as well as removal efficiencies of COD, TPh and color (at $\lambda=390 \mathrm{~nm})$ and specific electric energy consumption per unit of olive oil mill wastewater mass $\left(E_{\mathrm{EM}}\right)$.

\begin{tabular}{|c|c|c|c|c|c|c|c|c|}
\hline \multicolumn{5}{|c|}{ Independent variables matrix } & \multicolumn{3}{|c|}{ Removal efficiency } & \multirow[b]{2}{*}{$\begin{array}{l}E_{\mathrm{EM}} \\
\mathrm{g}^{-1} \mathrm{COD}_{\text {removed }}\end{array}$} \\
\hline Test & $\begin{array}{c}X_{1} \\
\mathrm{COD}^{\mathrm{mg} \mathrm{L}^{-1}}\end{array}$ & $\begin{array}{l}X_{2} \\
\mathrm{pH}\end{array}$ & $\begin{array}{c}X_{3} \\
t_{\text {contact }} \\
\text { hour }\end{array}$ & $\begin{array}{c}X_{4} \\
t_{\text {cycle }} \\
\text { minute }\end{array}$ & $\begin{array}{c}\mathrm{Y}_{1} \\
\mathrm{TPh} \\
\%\end{array}$ & $\begin{array}{c}\mathrm{Y}_{2} \\
\text { Color }(\lambda=390) \\
\%\end{array}$ & $\begin{array}{c}\mathrm{Y}_{3} \\
\mathrm{COD} \\
\%\end{array}$ & \\
\hline 1 & -1 & +1 & -1 & +1 & 56.6 & 19.0 & 27.8 & 2735 \\
\hline 2 & -1 & +1 & +1 & +1 & 83.3 & 49.0 & 41.3 & 5536 \\
\hline 3 & -1 & +1 & -1 & -1 & 57.1 & 32.7 & 37.2 & 2049 \\
\hline 4 & -1 & +1 & +1 & -1 & 87.3 & 65.7 & 52.5 & 4352 \\
\hline 5 & -1 & -1 & -1 & +1 & 64.9 & 45.5 & 18.6 & 4092 \\
\hline 6 & -1 & -1 & +1 & +1 & 91.0 & 76.6 & 59.3 & 3855 \\
\hline 7 & -1 & -1 & -1 & -1 & 63.5 & 49.8 & 34.0 & 2238 \\
\hline 8 & -1 & -1 & +1 & -1 & 86.1 & 77.4 & 56.5 & 4044 \\
\hline 9 & +1 & +1 & -1 & +1 & 26.3 & 21.6 & 35.2 & 308 \\
\hline 10 & +1 & +1 & +1 & +1 & 29.9 & 23.5 & 39.5 & 823 \\
\hline 11 & +1 & +1 & -1 & -1 & 23.5 & 16.9 & 34.9 & 311 \\
\hline 12 & +1 & +1 & +1 & -1 & 29.9 & 18.0 & 35.8 & 910 \\
\hline 13 & +1 & -1 & -1 & +1 & 34.8 & 42.7 & 29.7 & 366 \\
\hline 14 & +1 & -1 & +1 & +1 & 43.9 & 46.2 & 33.4 & 975 \\
\hline 15 & +1 & -1 & -1 & -1 & 31.0 & 34.4 & 37.3 & 291 \\
\hline 16 & +1 & -1 & +1 & -1 & 40.9 & 36.4 & 42.5 & 767 \\
\hline
\end{tabular}

the intermediates from the catalyst surface can result in the block of active sites on the catalyst, resulting in a reduction of the degradation rate. When the initial concentration is high, the number of active sites available is decreased by the phenolic compounds, and because the intensity of irradiation light was constant, the $\mathrm{OH}^{\bullet}$ and $\mathrm{O}_{2}{ }^{-\cdot}$ radicals formed on the surface of the catalyst were also constant; then, the attack of radicals on the compound molecules decreased while, simultaneously, the photodegradation efficiency decreases. At low concentration, the number of catalytic sites will not be a limiting factor and the degradation rate will be proportional to the substrate concentration, according to the apparent first-order kinetics (23).

The only variable that has a positive effect on the TPh removal is the treatment time. Indeed, an increase in $t_{\text {treatment }}$ from 8 to $24 \mathrm{~h}$ caused an increase in the removal efficiency from $45 \pm 17 \%$ to $62 \pm 28 \%$ (Table 2). However, a negative interaction effect between $t_{\text {treatment }}$ and initial COD [Eq. (2)] was detected. Indeed, the increase in substrate concentration can lead to the generation of intermediates, which may adsorb on the surface of the catalyst and gradually block the catalyst action. Also, the accumulation of fouling may cause the decrease of incident light and decrease the phenolic compounds degradation and decolorization efficiency.

The $\mathrm{pH}$ has a key effect on the oxidation potential of $\mathrm{OH}^{\bullet}$ radicals because of the direct relation of the oxidation potential with the $\mathrm{pH}$ value $(\mathrm{E} 0=2.8 \mathrm{~V}$ and $\mathrm{E} 14=1.95 \mathrm{~V})(24)$. In this study, $\mathrm{pH}$ was identified as a significant variable affecting negatively the TPh removal efficiency [Eq. (2)] and decolorization (see subsection Color removal), meaning that higher efficiencies will be obtained at lower $\mathrm{pH}$ values. TPh and Color removals efficiencies changed from $57 \pm 23 \%$ to $49 \pm 26 \%$ and from $51 \pm 17 \%$ to $31 \pm 18 \%$, when the initial $\mathrm{pH}$ was 4.8 and 7.5 , respectively (Table 2). Because the color removal is caused by phenolic compounds removal, the observed $\mathrm{pH}$ dependency can be explained by the fact that at $\mathrm{pH} 7.5$, the phenolic compounds (weak acids, with a $\mathrm{pKa}$ of 4.5) are fully dissociated (25), and the $\mathrm{TiO}_{2}$ surface is negatively charged (its point of zero charge "pzc" is 6.8) (26). Thus, at this $\mathrm{pH}$, there are repulsive forces between the negatively charged catalyst surface and the phenolic compounds, resulting in very low adsorption. At $\mathrm{pH} 4.5$, where the $\mathrm{TiO}_{2}$ surface is positively charged and the phenolic compounds are protonated, higher adsorption capacity can be achieved (27).

Color removal. Another problematic issue for the OMW treatment is its color. After the anaerobic treatment, the effluent did not accomplish the discharge limits (Table 1), presenting a strong dark color. $\mathrm{UV} / \mathrm{TiO}_{2}$ treatment can oxidize the colored phenolic compounds triggering the color removal. According to the factorial analysis, the main contributions for the color removal efficiency were the initial COD (33.4\% contribution), $\mathrm{pH}(28.5 \%)$ and $t_{\text {treatment }}(18.2 \%)$. Significant interactions must be considered namely, between COD and $t_{\text {treatment }}$ (13.8\%), COD and $t_{\text {contact }}(4.4 \%), \mathrm{pH}$ and $t_{\text {contact }}(1.2 \%)$. This can be described in the following model equation:

$$
\begin{aligned}
Y_{2}= & 41.0-11.0 Z_{1}-10.2 Z_{2}+8.1 Z_{3}-7.1 Z_{1} Z_{3} \\
& +4.0 Z_{1} Z_{4}-2.1 Z_{2} Z_{4}
\end{aligned}
$$

Where $Y_{2}$ is the color removal efficiency.

Effluent color decreased during the photo oxidation (Table 2). The main influence for the effluent decolorization efficiency is the initial COD concentration (and concomitant TPh concentration) because the effluent decolorization is coupled with the $\mathrm{TPh}$ degradation. The color removal efficiency represent around $68 \%$ of the $\mathrm{TPh}$ removal, in the experiments with $129 \mathrm{mg} \mathrm{TPh} \mathrm{L}^{-1}$, increasing to around $90 \%$ during the runs with $400 \mathrm{mg} \mathrm{TPh} \mathrm{L}^{-1}$. As expected, the OMW dark color is mainly due to the presence of phenolic compounds and their polymerized derivatives.

Increasing in the $t_{\text {treament }}$ positively influenced the color removal efficiency. However, this assumption must be carefully analyzed because of the interaction effect between $t_{\text {treatment }}$ and COD that negatively influences the process efficiency [Eq. (4)]. As explained in subsection total phenols removal, the increase in initial COD concentration may cause the gradual inactivation of active sites and consequently decrease the photoreactor efficiency. Confirmation of the previous interaction effect was 
Table 3. Predicted response variables by the factorial experimental design model.

\begin{tabular}{lcccccccc}
\hline Variable response & Prediction & SD & 95\% CI low & 95\% CI high & 95\% PI low & 95\% PI high & 95\% TI low & 95\% TI high \\
\hline TPh & 90.8 & 2.7 & 87.5 & 94.1 & 84.0 & 97.6 & 77.4 \\
Color & 79.3 & 1.9 & 76.4 & 82.1 & 74.1 & 84.4 & 69.0 & 89.3 \\
COD & 50.3 & 6.3 & 44.4 & 56.2 & 35.5 & 65.1 & 21.4
\end{tabular}

SD-The standard deviation estimated on the ANOVA. 95\% confidence interval (CI)-This is the low/high value of the 95\% CI in which you could expect to find the average response of a group of runs. 95\% PI-This is the low value of the prediction interval (PI) that will contain the true value of an individual observation with 95\% CI. 95\% TI-This is the lower bound of the tolerance interval (TI) containing a given proportion of all future outcomes with a given confidence level.

obtained by the decrease of the degradation rate in the longer tests, especially in the assays with $7370 \mathrm{mg} \mathrm{COD} \mathrm{L}^{-1}$. However, increasing the initial COD caused the removal efficiency decrease. This was expected because there are more molecules to be converted with the same incident light. Also, accumulation of wastes/fouling, especially with higher organic loadings, deteriorates the paper, causing the decrease in active sites and incident light intensity. This may explain why the color removal occurs mainly in the first hours of treatment.

Another important interaction occurs between initial COD and $t_{\text {contact }}$. It seems that to counterbalance the increase in COD concentration it is necessary to increase the contact time between the effluent and the catalyst. This may be achieved by decreasing the circulation flow rate. When we increase the circulation flow rate, the thickness of the liquid film increases and less photons reaches the photocatalyst surface. This results in slower production of hydroxyl radicals, and consequently, lower photocatalytic reaction rates.

COD removal. COD removal efficiency is almost unaffected by the $\mathrm{pH}$ and $t_{\text {contact }}$, however, the $t_{\text {treatment }}$ has a large positive influence, with $40.3 \%$ contribution to the model described by Eq. (5). The interaction effect of $t_{\text {treatment }}$ and initial COD has a negative effect over the COD removal efficiency with $27.2 \%$ contribution to the following model:

$$
Y_{3}=38.8+6.3 Z_{3}-5.2 Z_{1} Z_{3}
$$

Where $Y_{3}$ is the COD removal efficiency.

COD removal efficiency is directly linked with the treatment time. However, at high initial COD concentrations, due to the high energetic costs associated with this treatment, it is economically unfeasible to extend the treatment time until the legislation limits are achieved.

A substantial part of the initial COD is due to other compounds besides the phenolic compounds, which represent only $5-12 \%$ of the initial COD. These compounds, originally present in OMW or formed as secondary reaction by-products during the $\mathrm{AD}$ or photocatalysis steps, are more resistant to photocatalysis causing the difference between the COD and TPh removals efficiencies.

Once more is visible the negative influence of the $t_{\text {treatment }}$ and COD interaction [Eq. (5)]. This was detected for all the response variables $Y$, and was due to the deactivation of active sites and formation of intermediates that inhibit the photoreactor efficiency. Chatzisymeon and co-workers (28) used a similar approach but in a batch reactor with Degussa P25 $\mathrm{TiO}_{2}$ and obtained comparable results, although no significant interactions were detected. This main difference may be caused by the reactor characteristics. In a batch reactor with disperse catalyst and constant agitation the deactivation of active sites with time is not as significant as in an immobilized catalyst.

Table 3 shows the predicted values for the three response variables tested. Removal efficiencies of $90.8 \pm 2.7 \%, 79.3 \pm$ $1.9 \%$ and $50.3 \pm 6.3 \%$ for $\mathrm{TPh}$, color and COD, respectively, can be obtained with the experimental set up tested. In run 6 (Table 2), the maximum degradation of TPh (91\%) and COD (59\%) were achieved, whereas the color removal was $77 \%$. The difference between degradation rates of $\mathrm{TPh}$, color and COD could be explained by two factors: (1) the formation of small colorless organic molecules, which, at least temporarily, remain in the solution, for instance ethanol, glycerol and simple sugars, which can be considered as degradation intermediates; (2) the persistence, for varying periods of time, of only slightly colored or colorless macromolecules relatively resistant to the $\mathrm{UV} / \mathrm{TiO}_{2}$ attack, and hence likely to be carbohydrates (29). This is in good agreement with the interpretation of the $\mathrm{TiO}_{2}$ attack to OMW, i.e. preferential attack of the electron-rich aromatic and olefinic groups, and attack at a lower rate of aliphatic side chains and carbohydrates $(30,31)$.

A possibility to increase the process efficiency is to increase the incident light intensity. Laoufi and co-workers (22) tested different light power sources. Increasing the light intensity from 15 to $400 \mathrm{~W}$ enhanced phenol degradation from $15 \%$ to $100 \%$, after $4 \mathrm{~h}$ of irradiation. According to the authors, the photons present at high intensity were in excessive amounts leading to more reactive species generation and more destruction of phenol.

Energy consumption. One disadvantage of UV-photocatalysis is the need of energy that represents a bottleneck to the scale-up of this technique. As stated in subsection COD removal, the photocatalysis efficiency is linked with the UV lamp power $(22,32)$. The specific electric energy consumption per unit of pollutant mass $\left(E_{\mathrm{EM}}\right)$ $\left[\mathrm{kWh} \mathrm{kg}^{-1} \mathrm{COD}_{\text {removed }}\right]$ can be calculated from the formula (33):

$$
E_{\mathrm{EM}}=\frac{1000 P t}{V\left(C_{i}-C_{f}\right)}
$$

Where $P$ is the rated power of the UV lamp [kW], $V$ is the volume [L] of OMW treated in the time $t[\mathrm{~h}], C_{\mathrm{i}}$ and $C_{\mathrm{f}}$ are the initial and final COD concentration $\left[\mathrm{g} \mathrm{L}^{-1}\right]$ and the factor 1000 converts $\mathrm{g}$ to $\mathrm{kg}$.

The results show that this is an expensive technique, but the $E_{\mathrm{EM}}$ substantially decrease as the initial COD increases (Table 2). Similar results were obtained in (26), where photocatalysis was used for the OMW pretreatment. Currently, coupling a photocatalytic oxidation as a pretreatment aiming the effluent detoxification and a subsequent biological step is gaining relevance. However, although the OMW detoxification may be 
important, this approach has the weakness of not take full advantage of the real valorization potential of this effluent. By using appropriate measures, such as biological community adaptation and combining feeding phases with batch degradation (17), is possible to prevent the biological step inhibition and achieve the effluent valorization through the production of an energy biocarrier (biogas). Afterward, the photocatalysis step may be used to polish the final effluent quality, removing phenols and color. The integrated process can achieve the OMW valorization and overcome the economical issues associated with the photocatalytic step. Moreover, the inconvenience of effluent dilution and/or solids removal should be kept in mind because photocatalysis alone is not capable of treating effluents with high organic and solid loadings, which can be removed in the $\mathrm{AD}$ step.

Treatment time effect. A second experiment, with initial conditions close to the optimal previously defined by the factorial analysis, was performed to evaluate the effect of extend the treatment time beyond $24 \mathrm{~h}$. This parameter has been identified as having the highest positive effect in the models defined to maximize the removal efficiencies of phenols, color and COD. OMW initial COD was $1400 \mathrm{mg} \mathrm{L}^{-1}$, TPh were $75 \mathrm{mg} \mathrm{L}^{-1}, t_{\text {contact }}$ was $2 \mathrm{~min}$, and Color at $390 \mathrm{~nm}$ was $1.62 \mathrm{~cm}^{-1}$. COD, TPh and color removal efficiencies were followed during 72 h (Fig. 2).

$\mathrm{TPh}$ and color removal were almost complete $(>90 \%)$ after $24 \mathrm{~h}$ of operation. Fig. 3 shows the OMW samples at the beginning and after the treatment. The reactor efficiency to remove the OMW color is visible. However, the COD removal efficiency still increased from $38 \%(24 \mathrm{~h})$ to $65 \%(72 \mathrm{~h})$. If the fixed treatment time is too short, the intermediates remaining in solution could still be structurally similar to the initial biorecalcitrant compounds and therefore nonbiodegradable (24). However, the photocatalysis treatment time must be as short as possible to avoid high energy consumption, which represents about $60 \%$ of the total operational costs when using electric light sources (34). It was confirmed that a long treatment time is necessary to achieve an efficient COD removal. Therefore, a recirculation between the $\mathrm{AD}$ step and the photocatalytic reactor should be considered to degrade the residual COD.

\section{CONCLUSIONS}

A factorial experimental design was performed to optimize the performance of a photocatalytic reactor used for the posttreatment of olive mill wastewater. The Total phenols $(\mathrm{TPh})$ removal efficiency was highly dependent of the initial COD concentration, being almost completely oxidized after $24 \mathrm{~h}$. The color removal efficiency decreased with increasing COD concentration and $\mathrm{pH}$, and the COD removal efficiency was directly linked with the treatment time. Regarding the interaction effects, it was identified a negative effect between the initial COD and treatment time. Increasing the treatment time of effluents with high COD may cause the inactivation of active sites of the $\mathrm{TiO}_{2}$ paper, causing a drop in its efficiency. According to the factorial analysis, it is possible to obtain removal efficiencies of $90.8 \pm 2.7 \%, 79.3 \pm 1.9 \%$ and $50.3 \pm 6.3 \%$ for $\mathrm{TPh}$, color and COD, respectively, in the best operational scenario tested, i.e. low levels of COD, $\mathrm{pH}$ and $t_{\text {contact }}$, and high $t_{\text {treatment }}$.

Acknowledgements-The Portuguese Science Foundation (FCT) and the European Social Fund (ESF, POPH-QREN) gave financial support
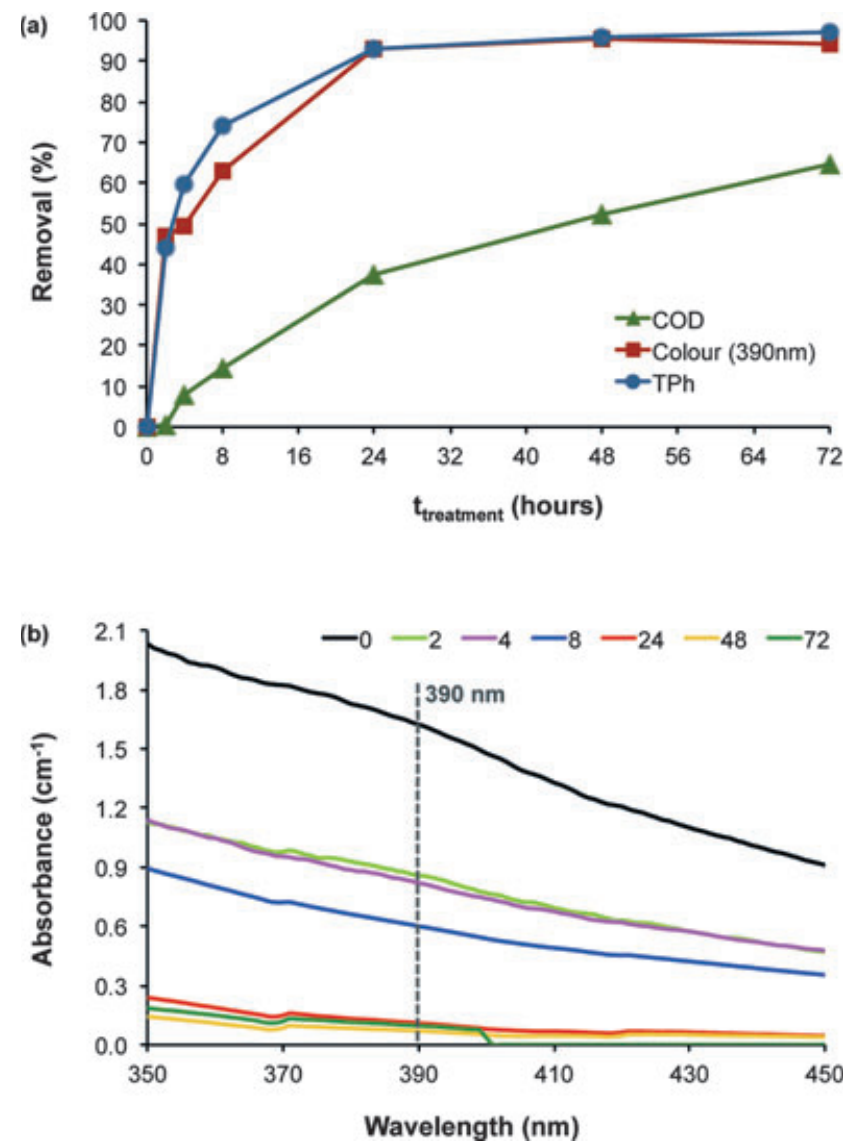

Figure 2. COD, TPh and Color (at $390 \mathrm{~nm}$ ) removal efficiencies in the photocatalytic reactor (a). UV-Visible $(350-450 \mathrm{~nm})$ spectra of oil mill wastewater during the photocatalytic treatment (b).

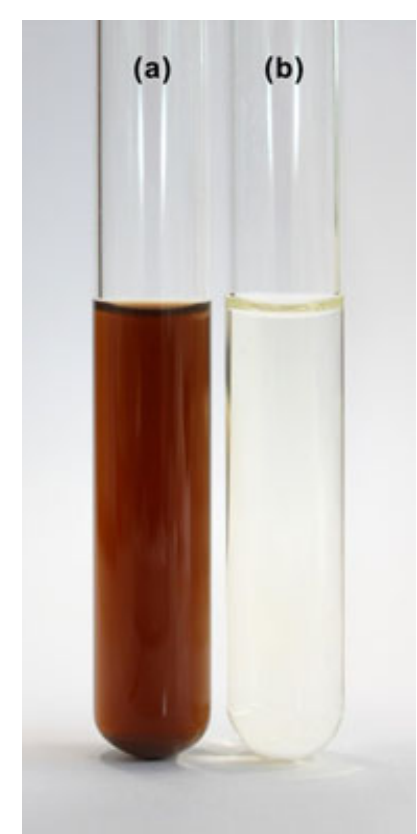

Figure 3. Olive oil mill wastewater pictures at the beginning (a) and at the end (b) of the photocatalytic treatment. 
through the Post-Doctoral grant attributed to José Carlos Costa (SFRH/ BDP/48 962/2008) and through the project PTDC/ENR/69 755/2006. The authors thank Dr. M.N. Pons and Dr. O. Zahraa the offer of the reactor and Mr Ing. J. Dussaud from Alstrohm (Pont-Evêque, France) for the $\mathrm{TiO}_{2}$ paper.

\section{REFERENCES}

1. Gernjak, W., M. I. Maldonado, S. Malato, J. Caceres, T. Krutzler, A. Glaser and R. Bauer (2004) Pilot-plant treatment of olive mill wastewater (OMW) by solar $\mathrm{TiO}_{2}$ photocatalysis and solar photo-Fenton. Sol. Energy 77, 567-572.

2. Azabou, S., W. Najjar, M. Bouaziz, A. Ghorbel and S. Sayadi (2010) A compact process for the treatment of olive mill wastewater by combining wet hydrogen peroxide catalytic oxidation and biological techniques. J. Hazard. Mater. 183, 62-69.

3. El-Gohary, F. A., M. I. Badawy, M. A. El-Khateeb and A. S. ElKalliny (2009) Integrated treatment of olive mill wastewater (OMW) by the combination of Fenton's reaction and anaerobic treatment. $J$. Hazard. Mater. 162, 1536-1541.

4. Benitez, F. J., J. Beltran-Heredia, J. Torregrosa, J. L. Acero and V. Cercas (1997) Aerobic degradation of olive mill wastewaters. Appl. Microbiol. Biot. 47, 185-188.

5. Ammary, B. Y. (2005) Treatment of olive mill wastewater using an anaerobic sequencing batch reactor. Desalination 177, 157-165.

6. Azbar, N., A. Bayram, A. A. Filibeli, A. Muezzinoglu, F. Sengul and A. Ozer (2004) A review of waste management options in olive oil production. Crit. Rev. Env. Sci. Tec. 34, 209-247.

7. Gonçalves, M. R., J. C. Costa, I. P. Marques and M. M. Alves (2011) Inoculum acclimation to oleate promotes the conversion of olive mill wastewater to methane. Energy 36, 2138-2141.

8. Niaounakis, M. and C. P. Halvadakis (2006) Olive Processing Waste Management: Literature Review and Patent Survey, 2nd ed. Elsevier. Oxford, England.

9. Chong, M. N., B. Jin, C. W. K. Chow and C. Saint (2010) Recent developments in photocatalytic water treatment technology: A review. Water Res. 44, 2997-3027.

10. Merabet, S., A. Bouzaz and D. Wolbert (2009) Photocatalytic degradation of indole in a circulating upflow reactor by $\mathrm{UV} / \mathrm{TiO}_{2}$ process - Influence of some operating parameters. J. Hazard. Mater. 166 1244-1249.

11. Fittipaldi, M., V. Gombac, A. Gasparotto, C. Deiana, G. Adami, D. Barreca, T. Montini, G. Martra, D. Gatteschi and P. Fornasiero (2011) Synergistic role of B and F dopants in promoting the photocatalytic activity of rutile $\mathrm{TiO}_{2}$. ChemPhysChem 12, 2221-2224.

12. Gombac, V., L. De Rogatis, A. Gasparotto, G. Vicario, T. Montini, D. Barreca, G. Balducci, P. Fornasiero, E. Tondello and M. Graziani (2007) $\mathrm{TiO}_{2}$ nanopowders doped with boron and nitrogen for photocatalytic applications. Chem. Phys. 339, 111-123.

13. Gaya, U. I. and A. H. Abdullah (2008) Heterogeneous photocatalytic degradation of organic contaminants over titanium dioxide: A review of fundamentals, progress and problems. J. Photoch. Photobio. C. 9, 1-12.

14. Miranda-Garcốa, N., M. Ignacio Maldonado, J. M. Coronado and S. Malato (2010) Degradation study of 15 emerging contaminants at low concentration by immobilized $\mathrm{TiO}_{2}$ in a pilot plant. Catal. Today 151, 107-113.

15. Miranda-Garcốa, N., S. Suárez, B. Sánchez, J. M. Coronado, S. Malato and M. Ignacio Maldonado (2011) Photocatalytic degradation of emerging contaminants of municipal wastewater treatment plant effluent using immobilized $\mathrm{TiO}_{2}$ in a solar pilot plant. Appl. Catal. B-Environ. 103, 294-301.

16. Merabet, S., D. Robert, J.-V. Weber, M. Bouhelassa and S. Benkhanouche (2009) Photocatalytic degradation of indole in $\mathrm{UV} / \mathrm{TiO}_{2}$ : Optimization and modelling using the response surface methodology (RSM). Environ. Chem. Lett. 7, 45-49.
17. Gonçalves, M. R., J. C. Costa, I. P. Marques and M. M. Alves (2012) Degradation of lipids and phenolics in the anaerobic treatment of olive mill wastewater: Feeding strategy and reactor configuration. Water Res. 46, 1684-1692.

18. Alinsafi, A., F. Evenou, E. M. Abdulkarim, M.-N. Pons, O. Zahraa, A. Benhammou, A. Yaacoubi and A. Nejmeddine (2007) Treatment of textile industry wastewater by supported photocatalysis. Dyes Pigm. 74, 439-445.

19. Guillard, C., J. Disdier, C. Monnet, J. Dussaud, S. Malato, J. Blanco, M. I. Maldonado and J.-M. Herrmann (2003) Solar efficiency of a new deposited titania photocatalyst: Chlorophenol, pesticide and dye removal applications. Appl. Catal. B-Environ. 46, 319-332.

20. American Public Health Association, American Water Works Association, Water Environment Federation (1998) Standard Methods for the Examination of Water and Wastewater, 20th edn. The Associations and Federation, Washington, DC.

21. Singleton, V. L. and J. A. Jr Rossi (1965) Colorimetry of total phenolics with phosphomolybdic phosphotungstic acid reagents. Am. J. Enol. Viticult. 16, 144-158.

22. Laoufi, N. A., D. Tassalit and F. Bentahar (2008) The degradation of phenol in water solution by $\mathrm{TiO}_{2}$ photocatalysis in a helical reactor. Global Nest J. 10, 404-418.

23. Hermann, J. M. (1999) Heterogeneous photocatalysis: Fundamentals and applications to the removal of various types of aqueous pollutants. Catal. Today 53, 115-129.

24. Badawy, M. I., F. El-Gohary, M. Y. Ghaly and M. E. M. Ali (2009) Enhancement of olive mill wastewater biodegradation by homogeneous and heterogeneous photocatalytic oxidation. J. Hazard. Mater. 169, 673-679.

25. Martell, E. and M. Smith (2003) Critical Stability Constants, Vol, 3. Plenum, New York and London.

26. Wiszniowski, J., D. Robert, J. Surmacz-Gorska, K. Miksch and J. V. Weber (2006) Leachate detoxification by combination of biological and $\mathrm{TiO}_{2}$-photocatalytic processes. Water Sci. Technol. 53(3), 181190.

27. Baransi, K., Y. Dubowski and I. Sabbah (2012) Synergetic effect between photocatalytic degradation and adsorption processes on the removal of phenolic compounds from olive mill wastewater. Water Res. 46, 789-798.

28. Chatzisymeon, E., N. P. Xekoukoulotakis and D. Mantzavinos (2009) Determination of key operating conditions for the photocatalytic treatment of olive mill wastewaters. Catal. Today 144, 143148.

29. El Hajjouji, H., F. Barje, E. Pinelli, J.-R. Bailly, C. Richard, P. Winterton, J.-C. Revel and M. Hafidi (2008) Photochemical UV/TiO treatment of olive mill wastewater (OMW). Bioresource Technol. 99, 7264-7269.

30. Machado, A. E. H., A. M. Furuyama, S. Z. Falone, R. Ruggiero, D. S. Perez and A. Castellan (2000) Photocatalytic degradation of lignin and lignin models, using titanium dioxide: The role of the hydroxyl radical. Chemosphere 40, 115-124.

31. Perez, D. S., A. Castellan, S. Grelier, M. G. H. Terrones, A. E. H. Machado, R. Ruggiero and A. L. Vilarinho (1998) Photochemical bleaching of chemical pulps catalyzed by titanium dioxide. J. Photoch. Photobio. A. 115, 73-80.

32. Silva, A. M. T., E. Nouli, N. P. Xekoukoulotakis and D. Mantzavinos (2007) Effect of key operating parameters on phenols degradation during $\mathrm{H}_{2} \mathrm{O}_{2}$-assisted $\mathrm{TiO}_{2}$ photocatalytic treatment of simulated and actual olive mill wastewaters. Appl. Catal. B-Envion. 73, 11-22.

33. Bolton, J. R., K. G. Bircher, W. Tumas and C. A. Tolman (2001) Figures-of-merit for the technical development and application of advanced oxidation technologies for both electric- and solar-driven systems. Pure Appl. Chem. 73, 627-637.

34. Sarria, V., S. Parra, M. Invernizzi, P. Peringer and C. Pulgarin (2001) Photochemical-biological treatment of a real industrial biorecalcitrant wastewater containing 5-amino-6-methyl-2-benzimidazolone. Water Sci. Technol. 44, 93-101. 